\begin{tabular}{|c|c|}
\hline Title & Luminescence properties of ZnO-M heterostructures fabricated by galvanic-submerged photosynthesis of crystallites \\
\hline Author(s) & Hiraiwa, Kento; Takahashi, Y uki; Mizuno, Junichi; Jeem, Melbert; W atanabe, Seiichi \\
\hline Citation & $\begin{array}{l}\text { A pplied surface science, 489, 269-277 } \\
\text { https://doi.org/10.1016/.apsusc.2019.05.292 }\end{array}$ \\
\hline Issue Date & 2019-09-30 \\
\hline Doc URL & http:/hdl .handle.net/2115/82834 \\
\hline Rights & $\begin{array}{l}\text { (02019. This manuscript version is made avail able under the CC-BY-NC-ND } 4.0 \text { license } \\
\text { http://creativecommons.org/icenses/by-nc-nd/4.0/ }\end{array}$ \\
\hline Rights(URL) & http://creativecommons.org/icenses/by-nc-nd/4.0/ \\
\hline Type & article (author version) \\
\hline Additional Information & There are other files related to this item in HUSCAP. Check the above URL. \\
\hline File Information & 20190306 Hiraiwa manuscript.pdf \\
\hline
\end{tabular}

Instructions for use 


\title{
Luminescence properties of $\mathrm{ZnO}-\mathrm{M}$ heterostructures fabricated by galvanic-submerged photosynthesis of crystallites
}

\author{
Kento Hiraiwa ${ }^{\mathrm{a}}$, Yuki Takahashi ${ }^{\mathrm{a}}$, Junichi Mizuno ${ }^{\mathrm{a}}$, Melbert Jeem ${ }^{\mathrm{b}}$, Seiichi Watanabe ${ }^{\mathrm{b}^{*}}$ \\ a'Graduate School of Engineering, Hokkaido University, N13, W8, Kita-ku, Sapporo, Hokkaido, \\ 060-8628, Japan. \\ bFaculty of Engineering, Hokkaido University, N13, W8, Kita-ku, Sapporo, Hokkaido, 060- \\ 8628, Japan. \\ * Corresponding author at: Faculty of Engineering, Hokkaido University, N13, W8, Kita-ku, Sapporo, \\ Hokkaido, 060-8628, Japan \\ Email address: sw004@eng.hokudai.ac.jp (S. Watanabe)
}

\begin{abstract}
By adapting hetero-nanostructures in optoelectronic device, a prominent luminescence characteristic can be obtained. The challenge is to engineer the band bending if a semiconducting surface gets contact with a metal. A galvanic replacement method is versatile for bimetallic heteronanostructures synthesis. However, the nanostructures morphologies can be varied depending on the metals pair or their supporting template. In this study, we demonstrate a facile 1-D $\mathrm{ZnO}$ nanorods (NRs) growth fabricated by galvanic replacement reactions. Without using bimetallic solution, the galvanic replacement reaction was implemented by joining $\mathrm{Zn}$ metal to $\mathrm{Au}, \mathrm{Pt}, \mathrm{Ag}, \mathrm{Cu}, \mathrm{W}$, and $\mathrm{Ni}$ metals substrate. The luminescence properties of $\mathrm{ZnO}$ NRs were characterized by photoluminescence (PL) and cathodoluminescence in scanning transmission electron microscopy (STEM-CL). Based on PL analysis result, oxygen vacancy $\left(\mathrm{V}_{O}\right)$ was responsible for the visible light region emission in all ZnO-M samples. Then, STEM-CL analysis highlighted the presence of zinc interstitial $\left(\mathrm{Zn}_{i}\right)$ at the interface of $\mathrm{ZnO}-\mathrm{M}$. Due to band bending, interaction between $\mathrm{V}_{O}$ and $\mathrm{Zn}_{i}$ resulted the formation of zinc antisite $\left(\mathrm{Zn}_{O}\right)$ at the interface. There was no shift in visible light emission of the NRs due to Fermi-level pinning. The findings will be useful for future large-scale synthesis and engineering of hetero-nanostructures luminescence devices.
\end{abstract}

\section{Introduction}

Semiconductor nanomaterials have been extensively studied for their applications in optoelectronic devices, catalysis, nanomedicines, and plasmonic devices [1-4]. Among them, optoelectronic devices are worthy of special attention. They have prominent role in revolutionizing the making of industry-wise technology ranging from transistors [5,6], light emitting diodes (LED) 
[7], gas sensors [8], and photovoltaics [9]. Most optoelectronic devices are made of III-V classes compounds: silicon (Si), gallium arsenide (GaAs), gallium nitride (GaN), etc. [10-12], appreciated by their appropriate range of bandgap energy. On the other hand, the classes of II-VI compounds, which includes zinc oxide ( $\mathrm{ZnO}$ ), zinc sulfide ( $\mathrm{ZnS}$ ), cadmium selenide (CdSe), etc. have been flourishing the study of nanodevices fabrication until present because of their several advantages towards the former.

$\mathrm{ZnO}$ particularly has many advantages from its wide bandgap energy $\left(\mathrm{E}_{\mathrm{g}}=3.37 \mathrm{eV}\right)$ and large exciton binding energy of $60 \mathrm{meV}$, more than twice than that of $\mathrm{GaN}$ and greater than thermal energies at room temperature $(25 \mathrm{meV})$. As n-type carrier, its high electron mobility and low toxicity properties has permitted this material to initiate ultraviolet (UV) emission at room temperature via exciton recombination process. This is necessary for low-cost and with prominent features devices such as LEDs, photovoltaics devices and lasers. And in this aspect, important point is the nanoscale fabrication opportunity for the material, where realization of nanostructures, such as nanorods or nanowires can enable the exploration of interesting $\mathrm{ZnO}$ properties based on quantum effects. Many methods have been employed for this purpose, including hydrothermal approaches, sol-gel, and deposition/precipitation [13-17]. Often, these methods engage with preparation of metal precursor and its adjusted metal salt. To achieve desired size, shape, and composition, the temperature and synthesis time are controlled in sensible way. Although great advances have been accomplished through these conventional methods, their consistency still remain a challenge.

In addition, there is a need for p-type or heterostructures circumventing p-ZnO, beneficial for innovation of optoelectronic devices with exclusive feature. However, this is far more difficult to achieve because formation of dopant at a shallow state in the bandgap level is usually inhibited by defects from opposite charge compensating impurities in $\mathrm{ZnO}[18,19]$. Those defects give rise to band bending $\left(\Delta \Phi_{\mathrm{Bв}}\right)$ at the heterojunction interface, which ultimately will affect the shift in work function $(\Delta \Phi)$ of the materials [20,21]. And detail study of $\Delta \Phi$ propitiate the level of donors-acceptors level and concentration, as well as the depletion width information that convolute into optoelectrical properties behavior of the heterostructures [22,23]. Meanwhile, empirical and calculation basis reports have established systematic results enabling us to reason the changing luminescence behavior of $p$-ZnO or organic/ZnO $[21,22,24]$. In this research, we wish to accommodate these fundamentals with our empirical approach results. And while maintaining environmentally benign approach of using only water and light, we demonstrate scalable $\mathrm{ZnO}$ nanorods (NRs) fabrication method. The adapted method: submerged photosynthesis of crystallites (SPSC) is a fashionable way to tune the optoelectrical properties of $\mathrm{ZnO}$ based on photo-induced radical reactions and water splitting process [25-28]. We also combine a galvanic replacement approach to SPSC (G-SPSC), utilizing metals of Au, $\mathrm{Pt}, \mathrm{Ag}, \mathrm{Cu}, \mathrm{W}$, and $\mathrm{Ni}$ but without using metal salt precursor. In this way, galvanic replacement become particularly interesting, as we only applied a contact of Zn-aforementioned metals (M) surface to allow 
galvanic based redox processes. As a consequence, the current synthesis time for SPSC is shorten while we still can maintain the synthesis of fine structures 1-D ZnO NRs.

In this study, photoluminescence measurement was implemented in order to study the luminescence properties of $\mathrm{ZnO}$ NRs. In addition, cathodoluminescence (CL) technique in scanning transmission electron microscopy (STEM) helped us to substantiate the heterostructures driven luminescence properties. This gives us a research goal in developing strategies for nanostructures fabrication with controlled surface morphologies and structure by means of galvanic replacement method, taking into account of photo-induced water splitting occurrence and nanostructures formation mechanism.

\section{Experimental details}

First, galvanic contact setup was performed by fixing Zn wire ( $\varphi 0.5 \mathrm{~mm}$, Nilaco, Japan) onto Au, Pt foil $(0.5 \times 17.5 \times 5$ mm, Nilaco, Japan $)$ and Ag, Cu, W, Ni plate $(0.5 \times 17.5 \times 5$ mm, Nilaco, Japan $)$ (Fig. 1). The plate samples surface was polished to make a uniform surface condition. Then, the sample is submerged in a $10 \mathrm{~mL}$ cell case filled with ultrapure water. Subsequently, the G-SPSC experiment is carried out by irradiating the sample with UV $\left(20 \mathrm{~mW} / \mathrm{cm}^{2}, \lambda=365 \mathrm{~nm}\right)$ light. Maximum UV irradiation was set to 48 hours at room temperature.

After G-SPSC, the surface morphology was observed with field emission scanning electron microscopy (FE-SEM, JEOL, JSM-7001FA). Elemental composition was analyzed by energy dispersive X-ray (EDX) equipped in the FE-SEM. Detailed NRs microstructure was studied and recorded by using a double Cs-corrected TEM (FEI, Titan cubed) operated at $300 \mathrm{kV}$. The crystal orientation of the surface of the sample was analyzed by X-ray diffraction (XRD, Rigaku, RINT 2500 HLB) with CuKa line ( $\lambda=1.5406 \AA$ ) and a scanning field of $5^{\circ} \leqq 2 \theta \leqq 100^{\circ}$. Peak fitting was done in reference to JCPDS cards 75-0576, 65-9743, 87-0720, 77-9662, 70-0989, 77-3491, and 87-0644 for $\mathrm{ZnO}, \mathrm{Cu}, \mathrm{Ag}, \mathrm{Au}, \mathrm{Ni}, \mathrm{W}$, and Pt, respectively. Chemical bonding state was analyzed by X-ray photoelectron spectroscopy (XPS, JEOL, JPS-9200). The XPS spectra were collected with a nominal energy resolution of $0.65 \mathrm{eV}$. Measurements were performed in ultrahigh vacuum chamber with a base pressure less than $1.0 \times 10^{-7}$. Spectra were acquired using a Mg Ka source $(\mathrm{h} v=1253.6 \mathrm{eV})$ operated at $10 \mathrm{kV}$. Data were collected in room temperature and all spectra were corrected with the C1s peak set at $285.0 \mathrm{eV}$.

A room temperature photoluminescence (PL) measurement was carried out to analyze the sample emission characteristic. Continuous-wave He-Cd laser $\left(\lambda_{\mathrm{ex}}=325 \mathrm{~nm}\right)$ was utilized as an excitation source and PL spectra were recorded using an Acton SP2150 imaging spectrograph (Princeton Instruments) with a nominal resolution of $0.4 \mathrm{~nm}$. Further, detailed emission characteristics were investigated by cathodoluminescence (CL, Gatan Vulcan CL Model 465 system) equipped in a S/TEM (JEOL, JEM2100) system operated at $200 \mathrm{kV}$. All STEM-CL spectra were collected in room 
temperature.

\section{Results and discussion}

G-SPSC 48h effect can be clearly seen from the diminished metallic luster of Zn-M samples (Fig. 2a) where whitish film appeared on the surface as the sign of ZnO NRs growth. Under UV ( $\lambda=365$ $\mathrm{nm}$ ) light, all the $\mathrm{M}(\mathrm{Au}, \mathrm{Pt}, \mathrm{Ag}, \mathrm{Cu}, \mathrm{W}, \mathrm{Ni}$ ) samples exhibited yellowish-orange luminescent while $\mathrm{Zn}$ wires at both end of M samples emitted shorter wavelength ( 400 nm) color (Fig. 2b). No distinct color change can be seen based on the photograph, despite the effect of ionization tendency (Table S1) of Zn vs M metals towards NRs formation (Fig. 2c). Clearly, higher weight change of M samples after G-SPSC occurred according to ionization tendency of $\mathrm{Zn}$ vs $\mathrm{M}$. In this case, $\Delta \mathrm{n}$ order is $\mathrm{Ni}<\mathrm{W}<\mathrm{Cu}$ $<\mathrm{Ag}<\mathrm{Pt}<\mathrm{Au}$. The initial FESEM images illustrate those order, which density pack of NRs ( $d: \sim 500$ $\mathrm{nm}, l: 1-3 \mu \mathrm{m}$ ) became greater following the increase of ionization tendency (Fig. 1c). The important highlight is the homogeneous vertical 1-D NRs growth on the surface. Vertical alignment can be attributed by similar a-plane of $\mathrm{M}$ samples with lattice constant of $\mathrm{ZnO}$ [29]. However in this study, uniform surface condition and deposition of metal oxide in locally alkaline environment played an important role, because uneven surface could result in rather nanoflowers formation[26,28]. In addition, the NRs have pencil-like tip, which attributed to oxygen-deficiency in $\mathrm{ZnO}$ stoichiometry [25].

Fig. 3 shows the XRD spectra for the NRs. The peaks are consistent with the hexagonal wurtzite phase of ZnO. Sharp peak at (002) (Fig. 3b) evidenced excellent growth direction and alignment of the NRs. A detail microstructure study using TEM indicated that all NRs appear to be single crystal wurtzite structure (Fig. 4a-c). HRTEM image shows planes of atoms perpendicular to the axial direction of the NR and a $0.26 \mathrm{~nm}$ distance between two (002) planes confirmed the NRs $c$-axis $<001>$ growth direction (Fig. 4d). This observation is also consistent with reported $\mathrm{ZnO}$ elsewhere [25,26,28]. The G-SPSC process does not neglect the production of hydroxide species related to $\mathrm{Zn}(\mathrm{OH})_{2}$. Those species particularly formed on the NRs surface, as measured by XPS (Fig. 6). Based on oxygen binding peaks $\mathrm{O} 1 \mathrm{~s}$ spectra, $\mathrm{Zn}(\mathrm{OH})_{2}$ can be assigned to $\sim 532 \mathrm{eV}$, while $\mathrm{Zn}-\mathrm{O}$ bonding at $\sim 531 \mathrm{eV}$ is still dominant throughout all the samples (see also Table S2) [30,31].

The NRs chemical and physical properties analyses above suggest the origin of yellowishorange luminescent of the samples (Fig. 2b). It is highly due to $\mathrm{ZnO}$ lattice defects comprised by oxygen vacancies $\left(\mathrm{V}_{O}\right)$, oxygen antisite defect $\left(\mathrm{O}_{z n}\right)$ as well as the inherent altered deep level transition in bandgap following the $\mathrm{ZnO}-\mathrm{M}$ heterostructure formation. Their formation can be well described according to the broad visible light emission in room-temperature PL spectra (Fig. 6). PL spectrum of ZnO-Cu sample was adopted for comparison with $\mathrm{ZnO}$ bulk sample because of its wellknown mechanism pertaining to p-n heterostructures formation [6,11,32-34]. In Fig. 6, ZnO-Cu exhibited no shift in $380 \mathrm{~nm}$ (3.26 eV) direct transition of near band edge (NBE) emission together 
with the $\mathrm{ZnO}$ bulk, although the latter has a much higher intensity. This is caused by high recombination rate of excited electron-hole pair that reflects intense energy absorption at NBE. And those absorption would not occur efficiently if defects transition exist in the bandgap. The ZnO bulk sample emitted $523 \mathrm{~nm}\left(2.37 \mathrm{eV}\right.$ ) peak, which is believed to be caused by $\mathrm{O}_{Z n}$ [25,35]. On the contrary, a broader range in this region was emitted by $\mathrm{ZnO}-\mathrm{Cu}$ sample, which $625 \mathrm{~nm}(1.98 \mathrm{eV})$ is the highest peak. The origin of $625 \mathrm{~nm}$ peak can be controversial, but the lack of oxygen based on chemical analyses and the lack of structure displayed by the pencil-like tip suggests that it is highly due to $\mathrm{V}_{O}$ [25]. A multiple level of $\mathrm{V}_{O}$ in the crystal lattice can be dominant in the broad range emission, acting as a nonradiative centers, and derail the NBE absorption. As a result, NBE emission is suppressed.

The identity of $625 \mathrm{~nm}$ peak in $\mathrm{ZnO}-\mathrm{Cu}$ must be clarified together with the heterojunction effect established by $\mathrm{ZnO}-\mathrm{Cu}$. However, the PL technique has a limitation in depth resolution by the absorption of light, typically tens of $\mathrm{nm}$ and limited lateral resolution to the wavelength of incident light. Thus, it is difficult to determine the defects segregation from the NR surfaces to the heterojunction interfaces by only referring to PL spectra. As alternatives or rather complementary, we can refer to extensive study of point defects in $\mathrm{ZnO}$ by theoretical techniques which include hybrid Hartree-Fock density functional [24] as well as first-principles calculation based on density functional theory [36-38]. Despite of theoretical and other leading spectroscopy characterization techniques, it is worthy to employ cathodoluminescence (CL) spectroscopy in STEM. By using STEM-CL technique, detail information from laterally localized defects on surfaces and depth resolved to within hundreds of nm of $\mathrm{ZnO}-\mathrm{Cu}$ interface can be obtained.

Fig. 7a shows a 2-D STEM-CL map on a $\mathrm{ZnO}-\mathrm{Cu}$ interface. The mapping region was set so that an independent $\mathrm{CL}$ spectrum can be extracted from the $\mathrm{ZnO}$ bulk surface and interface of $\mathrm{ZnO}-\mathrm{Cu}$ sample (Fig. 7b-c). Comparing the two parts, peak deconvolution via Gauss function results show two unchanged peaks at $380 \mathrm{~nm}$ (NBE) and $424 \mathrm{~nm}$. During STEM-CL mapping, electron irradiation would generate an excess of $\mathrm{V}_{O}$ and create $\mathrm{Cu}_{\mathrm{zn}}-\mathrm{V}_{O}[39,40]$ complex to suppress the visible light emission [41]. However, visible light emission remained strong on both positions. The possible explanation could be that the $\mathrm{Cu}_{\mathrm{Zn}}-\mathrm{V}_{O}$ complex is neutral, and competing reactions with active donors like $\mathrm{Zn}$ interstitial $\left(\mathrm{Zn}_{i}\right)$ prevail for the $424 \mathrm{~nm}$ peak appearance. This is logically true in terms of electron irradiation effect on $\mathrm{Zn}$ sublattice creating $\mathrm{Zn}_{i}[41]$ and the energy position of $\mathrm{Zn}_{i}$ at the donor level $\left(E_{D}\right)$ of ZnO bandgap [42]. Nevertheless, apparent alignment discrepancy in visible light region can be observed from $498-616 \mathrm{~nm}(2.49-2.01 \mathrm{eV})$ (Fig. 7b) and $523-625 \mathrm{~nm}(2.37-1.98 \mathrm{eV})$ (Fig. 7c) peaks on bulk surface and interface, respectively. In this respect, thermal runaway after lateral charge transfer from interface to the ZnO surface during the 2-D STEM-CL mapping could substantiate the higher visible light emission on surface.

Noting that the STEM-CL mapping was acquired in room-temperature condition, thermal runaway could generate more $\mathrm{V}_{O}$ defects, making the surface own a higher non-radiative 
recombination rate. There is also possibility of $\mathrm{Zn}_{i}$ participation in $\mathrm{V}_{O}$ (donor) - $\mathrm{O}_{\mathrm{Zn}}$ (acceptor) pair recombination process for the shift to occur. However, thermal runaway effect appeared to be more dominant due to higher $424 \mathrm{~nm}$ intensity on the surface. The interface has a distinguished peak at its $700 \mathrm{~nm}(1.77 \mathrm{eV}$ ) shoulder (Fig. 7c), marking the heterojunction of $\mathrm{ZnO}-\mathrm{Cu}$ interface. Later, we will discuss the role of aforementioned $\mathrm{Zn}_{i}$ and $\mathrm{V}_{O}$ to the formation of $700 \mathrm{~nm}$ energy, corroborated by the PL spectra results. For now, a surface defect presence contributing to the broadening of the visible light region cannot be overlooked. For $\mathrm{ZnO}$ case, this peak can be assigned to $735 \mathrm{~nm}$ [43]. Aside $\mathrm{Zn}_{i}$ and $\mathrm{V}_{O}$, band bending $\left(\Delta \Phi_{\mathrm{BB}}\right)$ at the interface of $\mathrm{ZnO}-\mathrm{Cu}$ also contribute to the shift in the visible light region.

Before further discuss about the $\Delta \Phi_{\mathrm{BB}}$ effect, the behavior of $\mathrm{V}_{O}$ and other present defects via PL excitation were examined in detail. Fig. 8a depicts a slight red shift in visible light region of the NRs following the ionization tendency $(\Delta \mathrm{n}: \mathrm{Ni}<\mathrm{W}<\mathrm{Cu}<\mathrm{Ag}<\mathrm{Pt}<\mathrm{Au})$. NBE emission at $380 \mathrm{~nm}$ remained consistent. The $\mathrm{V}_{O}$ at $(619-631) \mathrm{nm}$ is prominent for all ZnO-M samples (Table 1). The ZnO-M interface due peak can be assigned to 680 - $720 \mathrm{~nm}$ (Table 1). Now, during PL, in the case of $\mathrm{ZnO}, \Delta \Phi_{\mathrm{BB}}$ will occur when $\mathrm{ZnO}$ absorbs negative charge species atoms, particularly oxygencontaining species [44-46]. The absorption would take place in the vacancy defect sites $\left(\mathrm{V}_{O}\right)$ on the NR's surface, making the adsorbed species to gain negative charge. Subsequently, a depletion layer is formed on $\mathrm{ZnO}$. Herein, $\Delta \Phi_{\mathrm{BB}}$ occurrence followed. $\Delta \Phi_{\mathrm{BB}}$ increased when the He-Cd laser irradiation on $\mathrm{ZnO}$ creates electron-holes pair to desorb the former negative charges by their combination with the holes: $n$-type $\mathrm{ZnO}$ is obtained. The remaining free excited electrons give rise to the $n$-type conductivity as well as the visible light shift on the NRs luminescence. The $\Delta \Phi_{\mathrm{BB}}$ at $\mathrm{ZnO}-\mathrm{Cu}$ interface is the reason of $700 \mathrm{~nm}$ appearance in the range of $680-720 \mathrm{~nm}$ from all ZnO-M samples (Fig. 8b-g).

The STEM-CL result showed $\mathrm{Zn}_{i}$ on both the NRs surface and interface. But due to $\Delta \Phi_{\mathrm{BB}}$ at the interface, a complex of $\mathrm{Zn}_{i}$ and $\mathrm{V}_{O}$ creating zinc antisite $\left(\mathrm{Zn}_{O}\right)$ can be realized [38]. In $n$-type conductivity, $\mathrm{Zn}_{i}$ has a high formation energy under the Fermi-level position near the conduction band. It was peculiarly not detected in PL spectra due to its low concentration, which also is meaningful for compensation of $p$-type $\mathrm{ZnO}$ [38]. STEM-CL result indeed was very useful in clarifying the presence of $\mathrm{Zn}_{i}$. The complex formation $\mathrm{Zn}_{i}$ and $\mathrm{V}_{O}$ to be $\mathrm{Zn}_{O}$ can take place below the Fermi-level position (Fig. 9) and is perpendicular to the $c$-axis of $\mathrm{ZnO}$. During this formation, $\mathrm{Zn}_{i}$ interaction with $\mathrm{V}_{O}$ will also initiate the self-diffusion of $\mathrm{V}_{O}$ to become singly ionized oxygen $\left(\mathrm{V}_{O}{ }^{+}\right) . \mathrm{V}_{O}{ }^{+}$is unstable and will spontaneously relaxes into a lattice site nearest to substitutional oxygen atom and become oxygen interstitials $\left(\mathrm{O}_{i}\right)$ (Table 1) [1,38]. Overall, we could only address that the amount of $\mathrm{V}_{O}$ and its interaction with $\mathrm{Zn}_{i}$ at the interface to create $\mathrm{Zn}_{O}$ and $\mathrm{O}_{i}$ defects is responsible towards NBE emission behavior of all the $\mathrm{ZnO}-\mathrm{M}$ samples. The more formation of those defects will inhibit the NBE emission. In this case, NBE suppression order is $\mathrm{ZnO}-\mathrm{Pt} \rightarrow \mathrm{Ag} \rightarrow \mathrm{Au} \rightarrow \mathrm{Ni} \rightarrow \mathrm{W} \rightarrow \mathrm{Cu}$.

Clearly, the trend of NBE suppression is not occurring accordingly to the ionization tendency 
of M substrates vs Zn. It suggests that even when Schottky junction is established at the ZnO-M interface, the $\Delta \Phi_{\mathrm{BB}}$ influence towards the total change of work function $(\Delta \Phi)$ remain unclear. This is the key-point problem in engineering $p$-type $\mathrm{ZnO}$ nanostructures. The G-SPSC experiment resulted in 1-D NRs, which we can take account for geometrical effect towards the changing of $\mathrm{ZnO}$ when galvanically contacted with those metals [47]. In addition, surface plasmon resonance (SPR) on $\mathrm{Au}$ surface also can contribute to net flow of electrons flowing from $\mathrm{Au}$ to $\mathrm{ZnO}$, although we will not discuss SPR effect in detail in this paper. The consistent formation of 1-D NRs is related to uniform deposition of $\mathrm{Zn}^{2+}$ and $\mathrm{OH}^{-}$ions on the metals substrate surface, resulted by galvanic contact reaction and photo-induced water splitting process. A related work by the present authors was dedicated in understanding the photochemical mechanism during G-SPSC process [48].

Here, $\Delta \Phi_{\mathrm{BB}}$ curve as the function of defects concentration, i.e., $\mathrm{Zn}_{i}, \mathrm{~V}_{O}, \mathrm{Zn}_{O}$, and $\mathrm{O}_{i}$ can rather provide comprehensive description of this matter [21]. From all the metals, Pt has the highest work function $\left(\Phi_{\mathrm{Pt}}\right)$ of $5.65-6.1 \mathrm{eV}$ [49,50], followed by $\Phi_{\mathrm{Au}}: 5.1 \mathrm{eV}[51], \Phi_{\mathrm{W}}: 4.55-5.1 \mathrm{eV}[49,52]$, $\Phi_{\mathrm{Ni}}: 5.1 \mathrm{eV}[53], \Phi_{\mathrm{Ag}}: 4.2-4.26 \mathrm{eV}[49,54,55]$, and $\Phi_{\mathrm{Cu}}: 4-4.65 \mathrm{eV}[49,56]$. It is not easy to assign the work function of $\mathrm{ZnO}$, although some papers indicated $\Phi_{\mathrm{ZnO}}$ value at $4.3 \mathrm{eV}$ [54,55], relatively higher than that of $\Phi_{\mathrm{Ag}}$ to give rise the ohmic contact in the case of $\mathrm{ZnO}-\mathrm{Ag}$ sample. However, we observed strong PL visible light emission throughout all the ZnO-M samples, meaning that Schottky barrier is consistently established in all samples via G-SPSC treatment. The changing value of $\Phi$ is respective to the samples' surface plane orientation as well as the experimental conditions $[50,51,53]$.

Now, we consider that Schottky junction is established in all ZnO-M samples and their $\Delta \Phi$ is dominated $\Delta \Phi_{\mathrm{BB}}$. As mentioned above, $\Delta \Phi_{\mathrm{BB}}$ curve can be influenced by particularly the donor concentration. This is attributed by the width fitting of $\mathrm{Zn}_{O}$ and $\mathrm{O}_{i}$ in PL spectra, resulted from $\mathrm{Zn}_{i}$ interaction with $\mathrm{V}_{O}$. Less donor concentration means more $\Delta \Phi_{\mathrm{BB}}$ [21], however giving rise to easiness of $\mathrm{Zn}_{i}$ interaction with $\mathrm{V}_{O}$. This statement is in agreement with the non-appearing $424 \mathrm{~nm}$ peak in $\mathrm{PL}$ spectra, which is detected in STEM-CL experiment. Moreover, the $\mathrm{O}_{i}$ peak is the strongest in $\mathrm{ZnO}-\mathrm{Pt}$ sample, when $\Phi_{\mathrm{Pt}}-\Phi_{\mathrm{ZnO}}$ has the largest value. However, its appearance behavior is not consistently following the work function difference of $\Phi_{M}-\Phi_{Z n o}$. This would rather be contributed by the amount concentration of $\mathrm{V}_{O}$, its compensated negative charge absorption by $\mathrm{Zn}_{i}$ as well as the surface defects, all that are key-point to engineer in the future for prominent $\mathrm{ZnO}$ based heterojunction luminescent devices. The effect of work function difference does not essentially can influence the luminescence properties change in all $\mathrm{ZnO}-\mathrm{M}$ NRs. Their local interface seems to be in charge neutral, affected by Fermi level pinning [57,58], although the pinning is not strong given that a range in visible light (619 $-631 \mathrm{~nm}$ ) occurred. Nevertheless, the interaction of all metals, including the noble metals towards formation of $\mathrm{ZnO} \mathrm{NRs}$ is now understood and there is still room of improvement using G-SPSC fashion towards luminescent device application manufacturing in the future. 


\section{Conclusion}

In this work, we have demonstrated a galvanic replacement method in submerged photosynthesis (G-SPSC) of 1-D ZnO NRs combined with metals (M : Au, Pt, Ag, Cu, W, Ni). High ionization tendency of $\mathrm{M}$ vs $\mathrm{ZnO}$ affected a denser growth of $\mathrm{ZnO}$ NRs. The luminescence properties of the NRs were examined. On the basis of chemical analysis and PL technique, oxygen vacancies $\left(\mathrm{V}_{O}\right)$ contributed to visible light emission of the NRs. In particular, ZnO-M interface exhibited a peak shoulder at $700 \mathrm{~nm}$. This is resulted by interaction of zinc interstitial $\left(\mathrm{Zn}_{i}\right)$ with $\mathrm{V}_{O}$ to give rise the formation of zinc antisite $\mathrm{Zn}_{O}$. Oxygen interstitial $\left(\mathrm{O}_{i}\right)$ also produced as a result of $\mathrm{V}_{O}$ ionization. The $\mathrm{Zn}_{i}-\mathrm{V}_{O}$ interaction is initiated by the band bending at the $\mathrm{ZnO}-\mathrm{M}$ interface, despite the low concentration of $Z_{i}$ of non-appearing in the PL spectra. By implementation of STEM-CL mapping method, we manage to detect $\mathrm{Zn}_{i}$ at the $\mathrm{ZnO}-\mathrm{M}$ interface. The work function difference between the metals and $\mathrm{ZnO}$ does not affect the change in the visible light luminescence of the NRs. This is due to Fermi level pinning at the interface to make its neutral charge state.

\section{Acknowledgement}

This work was financially supported by the "Nanotechnology Platform" from the Ministry of Education, Culture, Sports, Science and Technology (MEXT). The authors are especially grateful to Professor S. Mutoh of Nagoya University for the help in STEM-CL experiment. All authors contributed equally to this work and declare no competing financial interest.

Fig. 1. Schematic diagram of (a) G-SPSC experiment and (b) ZnO NRs growth on metals substrate surface after G-SPSC.

Fig. 2. (a) Photographs of $\mathrm{ZnO}-\mathrm{M}$ samples under visible light and (b) their luminescence $(\lambda=365 \mathrm{~nm})$ after G-SPSC. (c) Weight change of ZnO-M samples after G-SPSC and their corresponding morphology by SEM images.

Fig. 3. (a) XRD patterns of $\mathrm{ZnO}-\mathrm{M}$ NRs and (b) the expanded significant $\mathrm{ZnO}$ peak.

Fig. 4. (a) TEM images of (a) $\mathrm{ZnO}-\mathrm{Au}$, (b) $\mathrm{ZnO}-\mathrm{Ag}$, (c) $\mathrm{ZnO}-\mathrm{Cu}$ on a quantifoil TEM grid. Inset is the SAED pattern obtained along the [11̄0] direction. (d) Representative ZnO NR with SAED pattern obtained along [1 $1 \overline{10}$ ] direction. Centre panel is its HRTEM image and right panel is the magnified inversed Fourier transformed image, obtained from the yellow marked area.

Fig. 5. (a) XPS spectra of O 1s state in (a) ZnO-Au, (b) ZnO-Pt, (c) ZnO-Ag, (d) ZnO-Cu, (f) ZnO-W, (g) $\mathrm{ZnO}-\mathrm{Ni}$. Peak fitting performed indicated the presence of $\mathrm{ZnO}$ in the oxygen lattice, $\mathrm{Zn}(\mathrm{OH})_{2}$ 
related to oxygen vacancy, and $\mathrm{H}_{2} \mathrm{O}$ related to chemisorbed oxygen species.

Fig. 6. (a) Photoluminescence spectra of perfect $\mathrm{ZnO}$ and $\mathrm{ZnO}-\mathrm{Cu}$ sample. Inset is color chromaticity diagram showing the color difference between $\mathrm{ZnO}$ and $\mathrm{ZnO}-\mathrm{Cu}$, yellowish green from $\mathrm{ZnO}$ and orange color from $\mathrm{ZnO}-\mathrm{Cu}$.

Fig. 7. (a) STEM backscattered electron image of ZnO-Cu. Yellow marker indicates the 2-D STEMCL mapping region, covering $\mathrm{ZnO}-\mathrm{Cu}$ interface and $\mathrm{ZnO}$ bulk surface. Red line is the 2-D mapping direction. Distinguished CL point spectra were obtained from (b) P1 - ZnO surface and (c) P2 - ZnO$\mathrm{Cu}$ interface.

Fig. 8. (a) Photoluminescence spectra of ZnO-M NRs according to ionization tendency ranking. Visible peaks vary according to metals. PL spectra with Gaussian fitting of (b) ZnO-Au (c) ZnO-Pt (d) $\mathrm{ZnO}-\mathrm{Ag}$ (e) $\mathrm{ZnO}-\mathrm{Cu}$ (f) $\mathrm{ZnO}-\mathrm{W}$ (g) $\mathrm{ZnO}-\mathrm{Ni}$.

Fig. 9. Schematic illustration of ZnO-M NRs luminescence mechanism.

\section{References}

[1] W. Zhu, S. Kitamura, M. Boffelli, E. Marin, E.D. Gaspera, M. Sturaro, A. Martucci, G. Pezzotti, Analysis of defect luminescence in Ga-doped ZnO nanoparticles, PCCP, 18 (2016) 9586-9593.

[2] X. Wu, J. Wang, G. Zhang, K.-i. Katsumata, K. Yanagisawa, T. Sato, S. Yin, Series of $\mathrm{MxWO}_{3} / \mathrm{ZnO}$ $(\mathrm{M}=\mathrm{K}, \mathrm{Rb}, \mathrm{NH} 4)$ nanocomposites: Combination of energy saving and environmental decontamination functions, Applied Catalysis B: Environmental, 201 (2017) 128-136.

[3] H. Sharma, K. Kumar, C. Choudhary, P.K. Mishra, B. Vaidya, Development and characterization of metal oxide nanoparticles for the delivery of anticancer drug, Artificial Cells, Nanomedicine, and Biotechnology, 44 (2016) 672-679.

[4] Y. Ruixuan, S. Tamaki, I. Junya, M. Xuan, L. Yanhua, W. Seiichi, Plasmonic surface nanostructuring of Au-dots@SiO 2 via laser-irradiation induced dewetting, Nanotechnology, 28 (2017) 275701.

[5] L.J. Brillson, W.T. Ruane, H. Gao, Y. Zhang, J. Luo, H. von Wenckstern, M. Grundmann, Spatiallyresolved cathodoluminescence spectroscopy of ZnO defects, Mater. Sci. Semicond. Process., 57 (2017) 197-209.

[6] C. Zhou, L. Xu, J. Song, R. Xing, S. Xu, D. Liu, H. Song, Ultrasensitive non-enzymatic glucose sensor based on three-dimensional network of $\mathrm{ZnO}-\mathrm{CuO}$ hierarchical nanocomposites by electrospinning, Sci. Rep., 4 (2014) 7382.

[7] T. Voss, S.R. Waldvogel, Hybrid LEDs based on ZnO nanowire structures, Mater. Sci. Semicond. Process., 69 (2017) 52-56. 
[8] D. Veeran Ponnuvelu, S. Abdulla, B. Pullithadathil, Highly monodispersed mesoporous, heterojunction ZnO@Au micro-spheres for trace-level detection of NO2 gas, Microporous Mesoporous Mater., 255 (2018) 156-165.

[9] A.B. Djurišić, X. Liu, Y.H. Leung, Zinc oxide films and nanomaterials for photovoltaic applications, physica status solidi (RRL) - Rapid Research Letters, 8 (2014) 123-132.

[10] Y. Zeng, X. Chen, Z. Yi, Y. Yi, X. Xu, Fabrication of p-n heterostructure ZnO/Si moth-eye structures: Antireflection, enhanced charge separation and photocatalytic properties, Appl. Surf. Sci., 441 (2018) 4048.

[11] Y.-S. Chen, C.-H. Liao, Y.-L. Chueh, C.-C. Lai, L.-Y. Chen, A.-K. Chu, C.-T. Kuo, H.-C. Wang, High performance $\mathrm{Cu}_{2} \mathrm{O} / \mathrm{ZnO}$ core-shell nanorod arrays synthesized using a nanoimprint GaN template by the hydrothermal growth technique, Opt. Mater. Express, 4 (2014) 1473-1486.

[12] D.Q. Tran, H.T. Pham, K. Higashimine, Y. Oshima, M. Akabori, Three-dimensional lattice rotation in GaAs nanowire growth on hydrogen-silsesquioxane covered GaAs (001) using molecular beam epitaxy, Physica E: Low-dimensional Systems and Nanostructures, 99 (2018) 58-62.

[13] J. Joo, B.Y. Chow, M. Prakash, E.S. Boyden, J.M. Jacobson, Face-selective electrostatic control of hydrothermal zinc oxide nanowire synthesis, Nat. Mater., 10 (2011) 596-601.

[14] G.J. Hutchings, C.J. Kiely, Strategies for the Synthesis of Supported Gold Palladium Nanoparticles with Controlled Morphology and Composition, Acc. Chem. Res., 46 (2013) 1759-1772.

[15] P. Munnik, P.E. de Jongh, K.P. de Jong, Recent Developments in the Synthesis of Supported Catalysts, Chem. Rev., 115 (2015) 6687-6718.

[16] J. El Ghoul, C. Barthou, L. El Mir, Synthesis by sol-gel process, structural and optical properties of nanoparticles of zinc oxide doped vanadium, Superlattices Microstruct., 51 (2012) 942-951.

[17] S. Cousy, N. Gorodylova, L. Svoboda, J. Zelenka, Influence of synthesis conditions over simonkolleite/ZnO precipitation, Chem Pap, 71 (2017) 2325-2334.

[18] D.C. Look, B. Claflin, P-type doping and devices based on ZnO, physica status solidi (b), 241 (2004) 624-630.

[19] J. Robertson, Disorder, band offsets and dopability of transparent conducting oxides, Thin Solid Films, 516 (2008) 1419-1425.

[20] O.T. Hofmann, P. Rinke, Band Bending Engineering at Organic/Inorganic Interfaces Using Organic Self-Assembled Monolayers, Advanced Electronic Materials, 3 (2017) 1600373.

[21] R. Schlesinger, Y. Xu, O.T. Hofmann, S. Winkler, J. Frisch, J. Niederhausen, A. Vollmer, S. Blumstengel, F. Henneberger, P. Rinke, M. Scheffler, N. Koch, Controlling the work function of ZnO and the energy-level alignment at the interface to organic semiconductors with a molecular electron acceptor, Phys. Rev. B, 87 (2013) 155311.

[22] K.G. Saw, S.S. Tneh, F.K. Yam, S.S. Ng, Z. Hassan, Determination of Acceptor Concentration, Depletion Width, Donor Level Movement and Sensitivity Factor of ZnO on Diamond Heterojunction under 
UV Illumination, PLoS One, 9 (2014) e89348.

[23] J.L. Lyons, A. Alkauskas, A. Janotti, C.G.V.d. Walle, Deep donor state of the copper acceptor as a source of green luminescence in ZnO, Appl. Phys. Lett., 111 (2017) 042101.

[24] F. Oba, A. Togo, I. Tanaka, J. Paier, G. Kresse, Defect energetics in ZnO: A hybrid Hartree-Fock density functional study, Phys. Rev. B, 77 (2008) 245202.

[25] M. Jeem, L. Zhang, J. Ishioka, T. Shibayama, T. Iwasaki, T. Kato, S. Watanabe, Tuning Optoelectrical Properties of ZnO Nanorods with Excitonic Defects via Submerged Illumination, Nano Lett., 17 (2017) 2088-2093.

[26] M. Jeem, M.R.M. bin Julaihi, J. Ishioka, S. Yatsu, K. Okamoto, T. Shibayama, T. Iwasaki, T. Kato, S. Watanabe, A pathway of nanocrystallite fabrication by photo-assisted growth in pure water, Sci. Rep., 5 (2015) 11429.

[27] F. Nishino, M. Jeem, L. Zhang, K. Okamoto, S. Okabe, S. Watanabe, Formation of CuO nano-flowered surfaces via submerged photo-synthesis of crystallites and their antimicrobial activity, Sci. Rep., 7 (2017) 1063.

[28] L. Zhang, M. Jeem, K. Okamoto, S. Watanabe, Photochemistry and the role of light during the submerged photosynthesis of zinc oxide nanorods, Sci. Rep., 8 (2018) 177.

[29] F.M. Li, G. Hsieh, S. Dalal, M.C. Newton, J.E. Stott, P. Hiralal, A. Nathan, P.A. Warburton, H.E. Unalan, P. Beecher, A.J. Flewitt, I. Robinson, G. Amaratunga, W.I. Milne, Zinc Oxide Nanostructures and High Electron Mobility Nanocomposite Thin Film Transistors, IEEE Trans. Electron Devices, 55 (2008) 3001-3011.

[30] W. Lu, Y. Dong, C. Li, Y. Xia, B. Liu, J. Xie, N. Li, Y. Zhang, Preparation of ZnO films with variable electric field-assisted atomic layer deposition technique, Appl. Surf. Sci., 303 (2014) 111-117.

[31] N. Neykova, Y.-Y. Chang, M. Buryi, M. Davydova, R. Kucerkova, D. Simek, Z. Remes, O. PopGeorgievski, Study of ZnO nanorods grown under UV irradiation, Appl. Surf. Sci., 472 (2019) 105-111.

[32] K. Wang, X. Qian, L. Zhang, Y. Li, H. Liu, Inorganic-organic p-n heterojunction nanotree arrays for a high-sensitivity diode humidity sensor, ACS Appl Mater Interfaces, 5 (2013) 5825-5831.

[33] I.C. Wu, Y.-H. Weng, M.-Y. Lu, C.-P. Jen, V.E. Fedorov, W.C. Chen, M.T. Wu, C.-T. Kuo, H.-C. Wang, Nano-structure $\mathrm{ZnO} / \mathrm{Cu}_{2} \mathrm{O}$ photoelectrochemical and self-powered biosensor for esophageal cancer cell detection, Opt. Express, 25 (2017) 7689-7706.

[34] A. Kargar, Y. Jing, S.J. Kim, C.T. Riley, X. Pan, D. Wang, ZnO/CuO heterojunction branched nanowires for photoelectrochemical hydrogen generation, ACS Nano, 7 (2013) 11112-11120.

[35] S.K. Mishra, S. Srivastava, R.K. Srivastava, A.C. Panday, S.G. Prakash, Photoluminescence and ultraviolet photoresponse in $\mathrm{ZnO}$ nanophorsphors prepared by thermal decomposition of zinc acetate, Adv. Mater. Lett., 2 (2011) 298-302.

[36] A. Janotti, C.G. Van de Walle, Fundamentals of zinc oxide as a semiconductor, Rep. Prog. Phys., 72 (2009) 126501. 
[37] A.F. Kohan, G. Ceder, D. Morgan, C.G. Van de Walle, First-principles study of native point defects in ZnO, Phys. Rev. B, 61 (2000) 15019-15027.

[38] A. Janotti, C.G. Van de Walle, Native point defects in ZnO, Phys. Rev. B, 76 (2007) 165202.

[39] N.Y. Garces, L. Wang, L. Bai, N.C. Giles, L.E. Halliburton, G. Cantwell, Role of copper in the green luminescence from ZnO crystals, Appl. Phys. Lett., 81 (2002) 622-624.

[40] R. Dingle, Luminescent Transitions Associated With Divalent Copper Impurities and the Green Emission from Semiconducting Zinc Oxide, Phys. Rev. Lett., 23 (1969) 579-581.

[41] K.E. Knutsen, A. Galeckas, A. Zubiaga, F. Tuomisto, G.C. Farlow, B.G. Svensson, A.Y. Kuznetsov, Zinc vacancy and oxygen interstitial in $\mathrm{ZnO}$ revealed by sequential annealing and electron irradiation, Phys. Rev. B, 86 (2012) 121203.

[42] B. Lin, Z. Fu, Y. Jia, Green luminescent center in undoped zinc oxide films deposited on silicon substrates, Appl. Phys. Lett., 79 (2001) 943-945.

[43] H.C. Ong, G.T. Du, The evolution of defect emissions in oxygen-deficient and -surplus $\mathrm{ZnO}$ thin films: the implication of different growth modes, J. Cryst. Growth, 265 (2004) 471-475.

[44] O. Schmidt, A. Geis, P. Kiesel, C.G. Van de Walle, N.M. Johnson, A. Bakin, A. Waag, G.H. Döhler, Analysis of a conducting channel at the native zinc oxide surface, Superlattices Microstruct., 39 (2006) 816.

[45] Z. Fan, D. Wang, P.-C. Chang, W.-Y. Tseng, J.G. Lu, ZnO nanowire field-effect transistor and oxygen sensing property, Appl. Phys. Lett., 85 (2004) 5923-5925.

[46] Q.H. Li, Y.X. Liang, Q. Wan, T.H. Wang, Oxygen sensing characteristics of individual ZnO nanowire transistors, Appl. Phys. Lett., 85 (2004) 6389-6391.

[47] X. Bai, E.G. Wang, P. Gao, Z.L. Wang, Measuring the Work Function at a Nanobelt Tip and at a Nanoparticle Surface, Nano Lett., 3 (2003) 1147-1150.

[48] Y. Takahashi, K. Hiraiwa, M. Jeem, L. Zhang, S. Watanabe, Galvanic-submerged photosynthesis of crystallites: Fabrication of ZnO nanorods@Cu-surface, to be published, (2019).

[49] H.B. Michaelson, The work function of the elements and its periodicity, J. Appl. Phys., 48 (1977) 4729-4733.

[50] G.N. Derry, Z. Ji-Zhong, Work function of Pt(111), Phys. Rev. B, 39 (1989) 1940-1941.

[51] S. Osella, D. Cornil, J. Cornil, Work function modification of the (111) gold surface covered by long alkanethiol-based self-assembled monolayers, PCCP, 16 (2014) 2866-2873.

[52] L. van Someren, Work function measurements on macroscopic tungsten specimens, Surf Sci., 20 (1970) 221-234.

[53] B.G. Baker, B.B. Johnson, G.L.C. Maire, Photoelectric work function measurements on nickel crystals and films, Surf Sci., 24 (1971) 572-586.

[54] W. He, H. Wu, W.G. Wamer, H.-K. Kim, J. Zheng, H. Jia, Z. Zheng, J.-J. Yin, Unraveling the Enhanced Photocatalytic Activity and Phototoxicity of ZnO/Metal Hybrid Nanostructures from Generation of 
Reactive Oxygen Species and Charge Carriers, ACS Appl. Mater. Interfaces, 6 (2014) 15527-15535.

[55] L.-L. Tan, W.-J. Ong, S.-P. Chai, A.R. Mohamed, Noble metal modified reduced graphene oxide/ $/ \mathrm{TiO}_{2}$ ternary nanostructures for efficient visible-light-driven photoreduction of carbon dioxide into methane, Applied Catalysis B: Environmental, 166-167 (2015) 251-259.

[56] V. Dose, W. Altmann, A. Goldmann, U. Kolac, J. Rogozik, Image-Potential States Observed by Inverse Photoemission, Phys. Rev. Lett., 52 (1984) 1919-1921.

[57] M. Schlüter, Chemical trends in metal-semiconductor barrier heights, Phys. Rev. B, 17 (1978) 50445047.

[58] A.J. Bard, A.B. Bocarsly, F.R.F. Fan, E.G. Walton, M.S. Wrighton, The concept of Fermi level pinning at semiconductor/liquid junctions. Consequences for energy conversion efficiency and selection of useful solution redox couples in solar devices, J. Am. Chem. Soc., 102 (1980) 3671-3677. 


\section{Luminescent properties of $\mathrm{ZnO}-\mathrm{M}$ heterostructures fabricated}

by Galvanic-submerged photosynthesis of crystallites

\section{ALL FIGURES}

Kento Hiraiwa, Yuki Takahashi, Juinchi Mizuno, Melbert Jeem, Seiichi Watanabe 


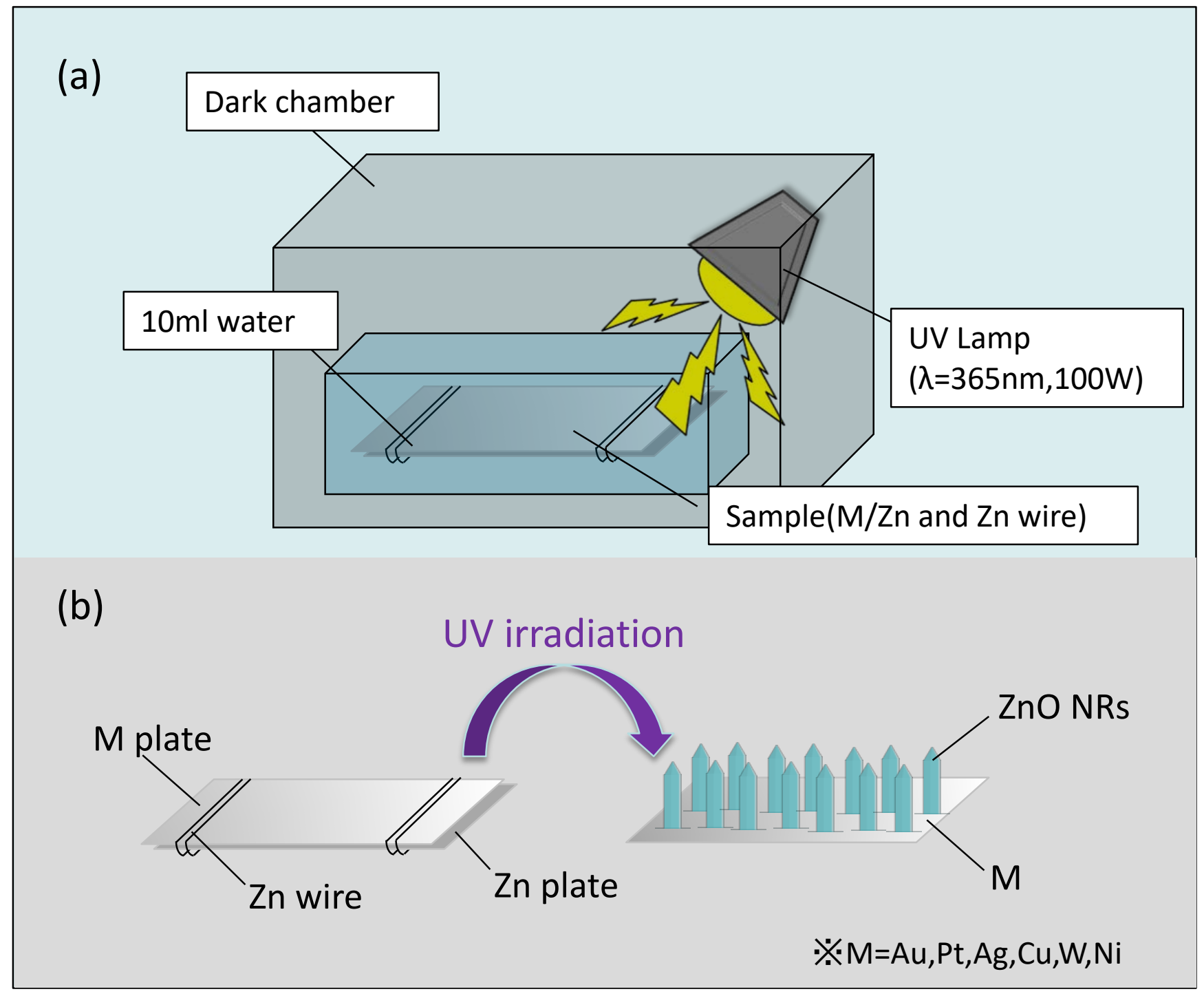

Fig. 1. Schematic diagram of (a) G-SPSC experiment and (b) ZnO NRs growth on noble metals surface after G-SPSC. 


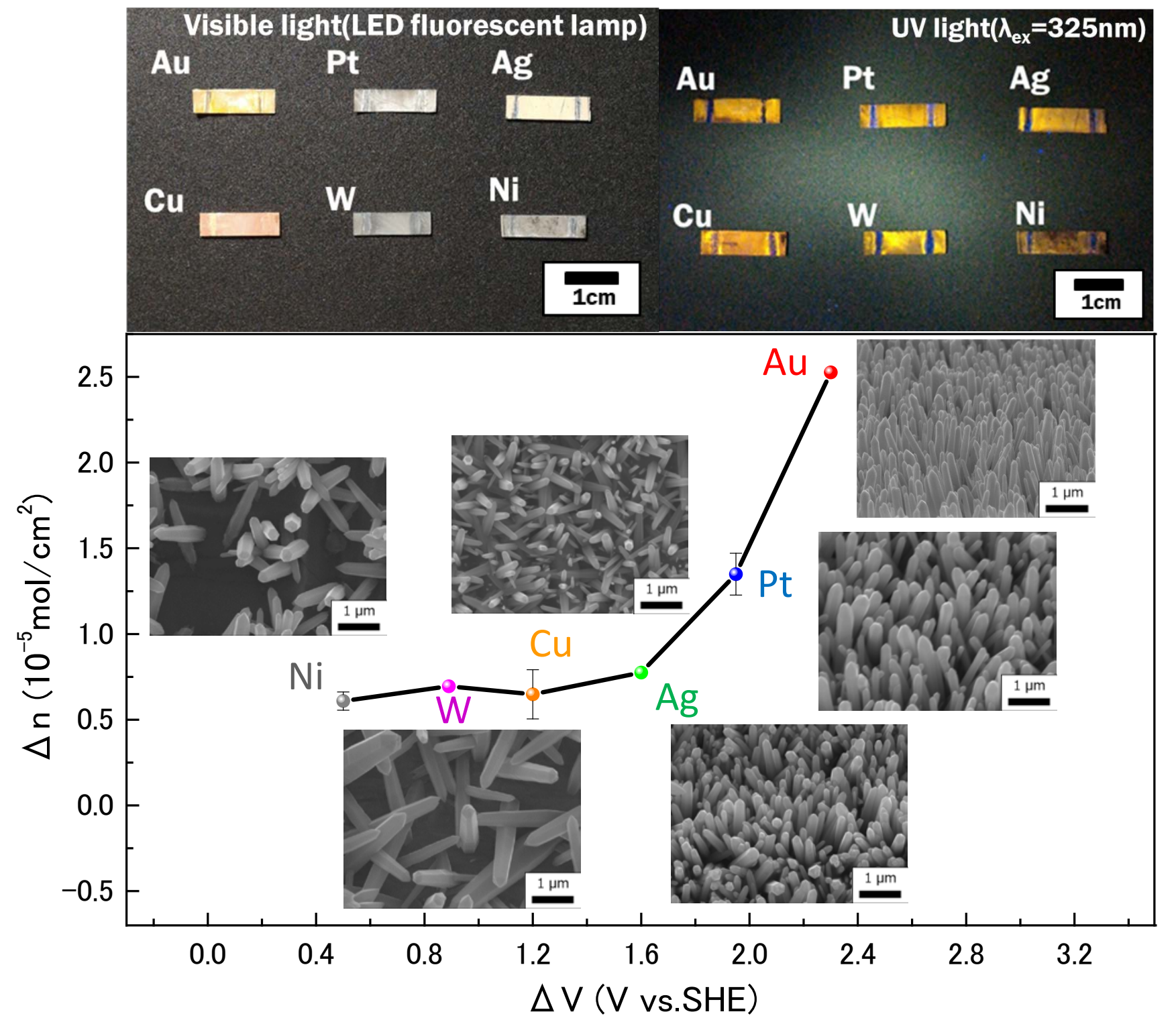

Fig. 2. (a) Photographs of $\mathrm{ZnO}-\mathrm{M}$ samples under visible light and (b) their luminescence $(\lambda=365 \mathrm{~nm})$ after G-SPSC. (c) Weight change of ZnO-M samples after G-SPSC and their corresponding morphology by SEM images. 

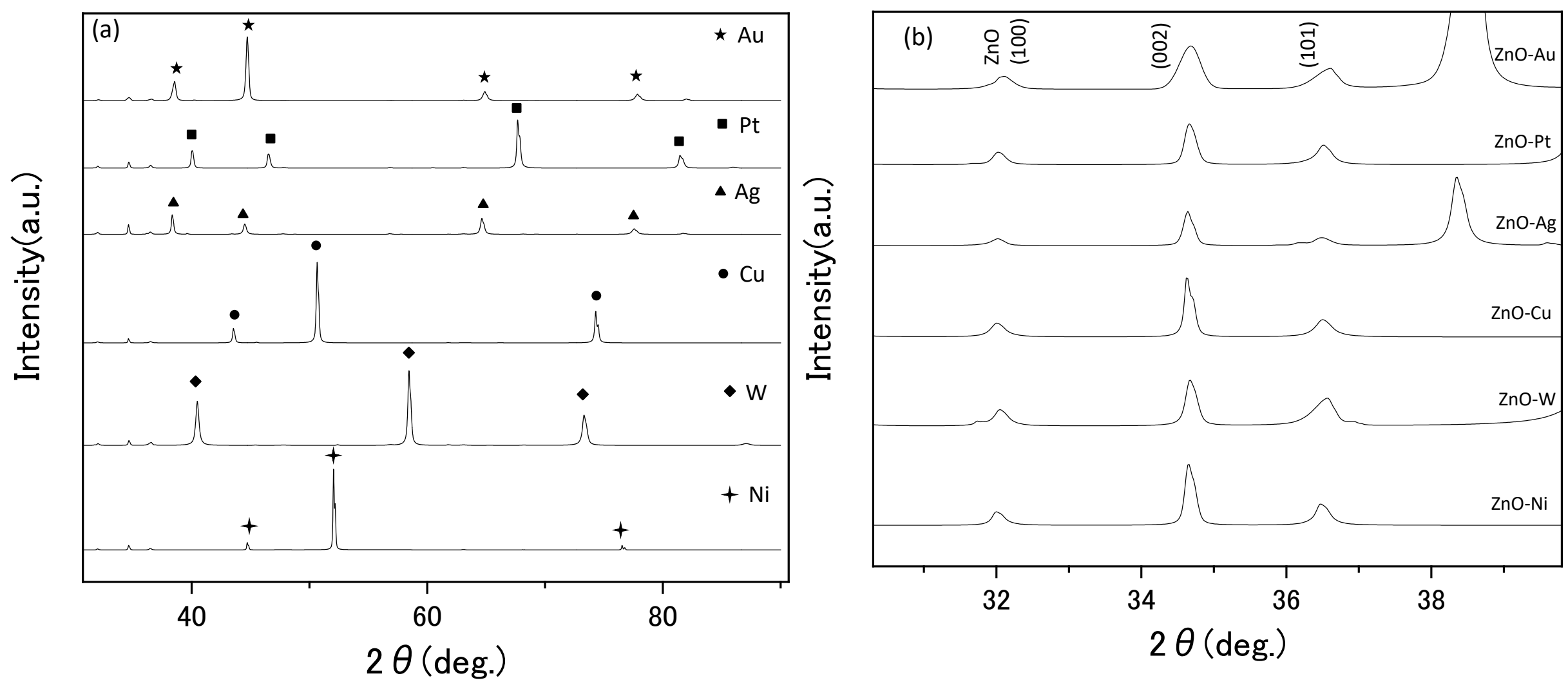

Fig. 3. (a) XRD patterns of $\mathrm{ZnO}-\mathrm{M}$ NRs and (b) the expanded significant $\mathrm{ZnO}$ peak. 
TEM ZnO-Auを追加

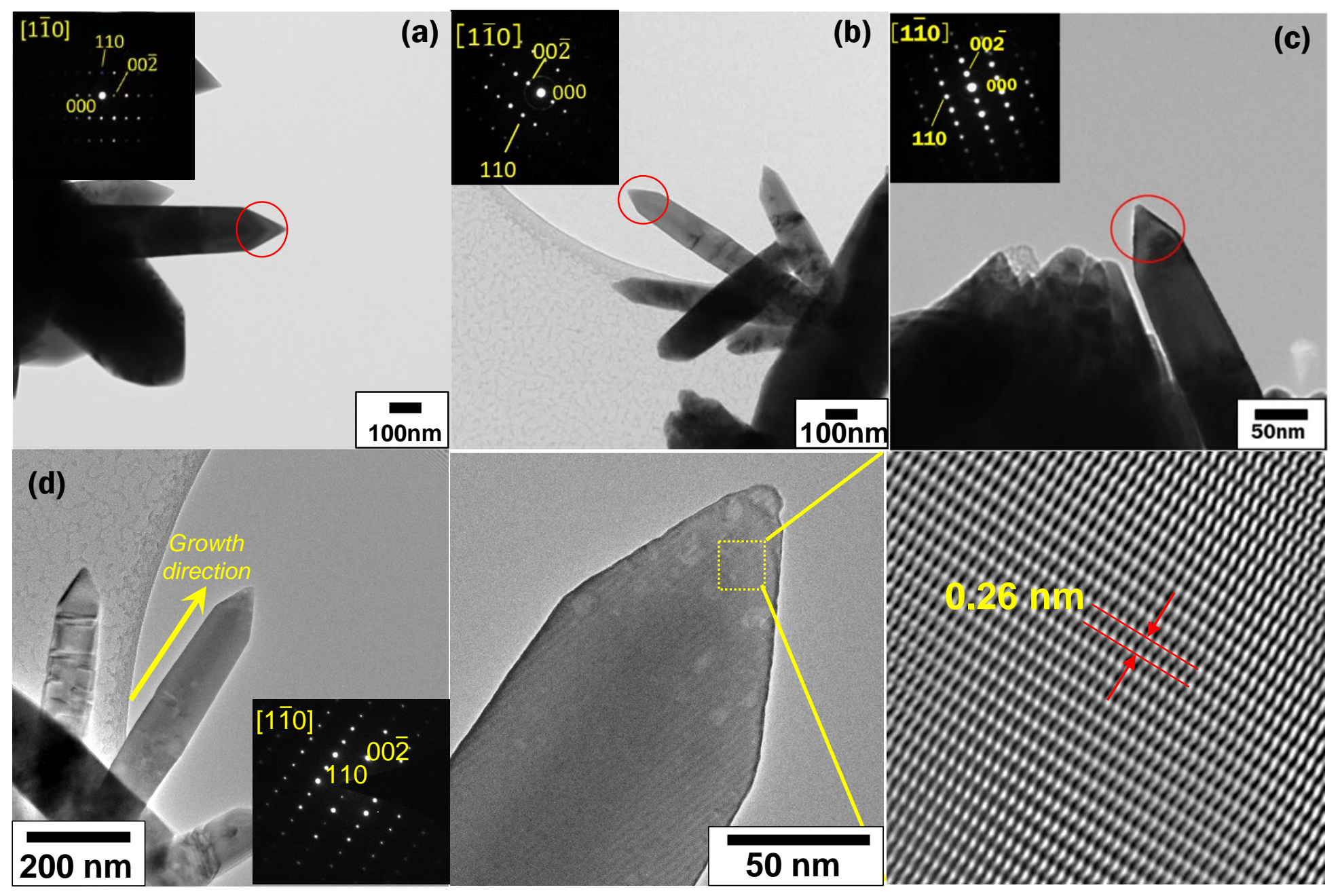

Fig. 4. (a) TEM images of (a) $\mathrm{ZnO}-\mathrm{Au}$, (b) $\mathrm{ZnO}-\mathrm{Ag}$, (c) $\mathrm{ZnO}-\mathrm{Cu}$ on a quantifoil TEM grid. Inset is the SAED pattern obtained along the [110] direction. (d) Representative ZnO NR with SAED pattern obtained along [110] direction. Centre panel is its HRTEM image and right panel is the magnified inversed Fourier transformed image, obtained from the yellow marked area. 


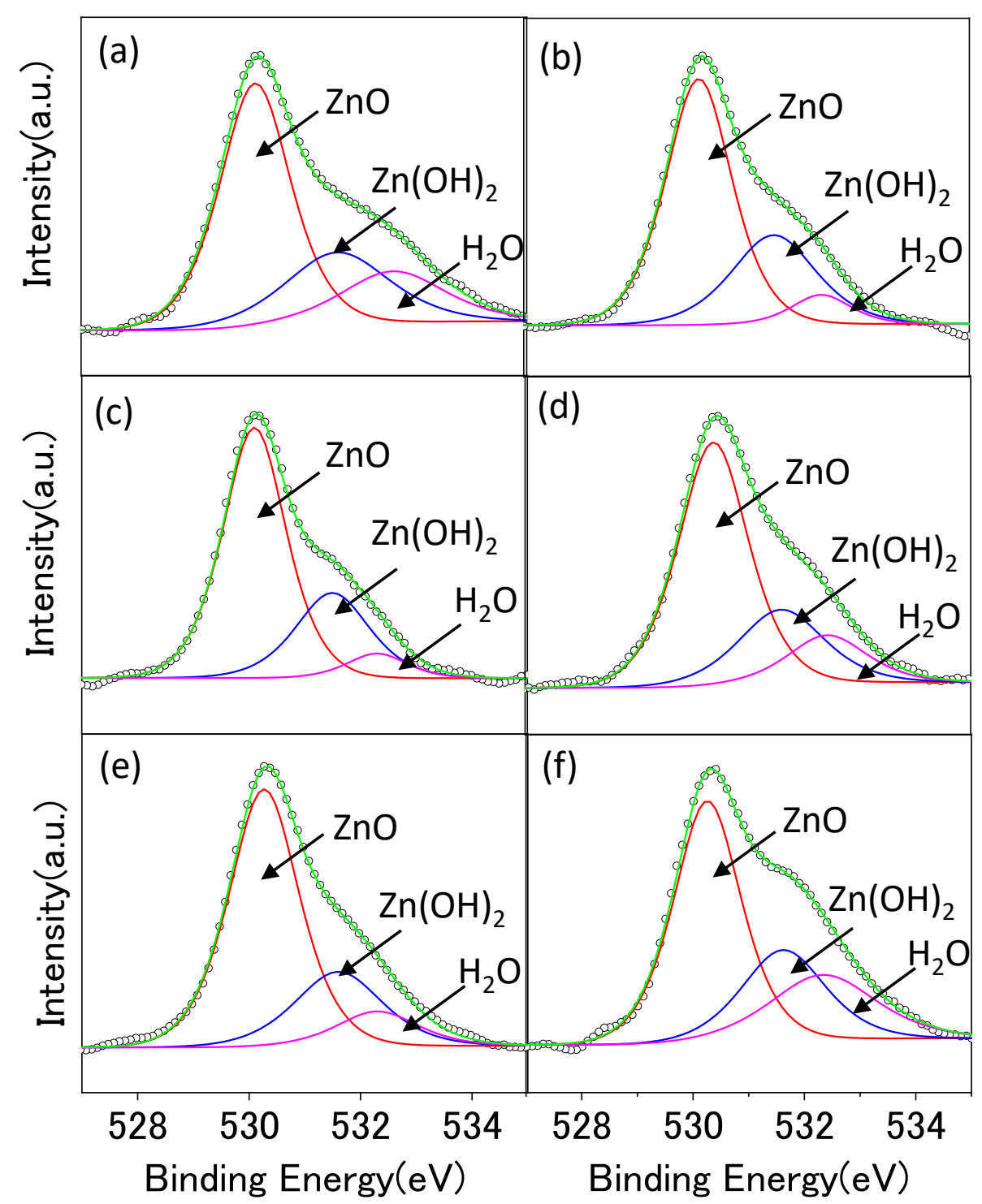

Fig. 5. (a) XPS spectra of $\mathrm{O}$ 1s state in (a) $\mathrm{ZnO}-\mathrm{Au}$, (b) $\mathrm{ZnO}-\mathrm{Pt}$, (c) $\mathrm{ZnO}-\mathrm{Ag}$, (d) $\mathrm{ZnO}-\mathrm{Cu}$, (f) $\mathrm{ZnO}-\mathrm{W}$, (g) $\mathrm{ZnO}-\mathrm{Ni}$. Peak fitting performed indicated the presence of $\mathrm{ZnO}$ in the oxygen lattice, $\mathrm{Zn}(\mathrm{OH})_{2}$ related to oxygen vacancy, and $\mathrm{H}_{2} \mathrm{O}$ related to chemisorbed oxygen species. 
$\mathrm{PL}$

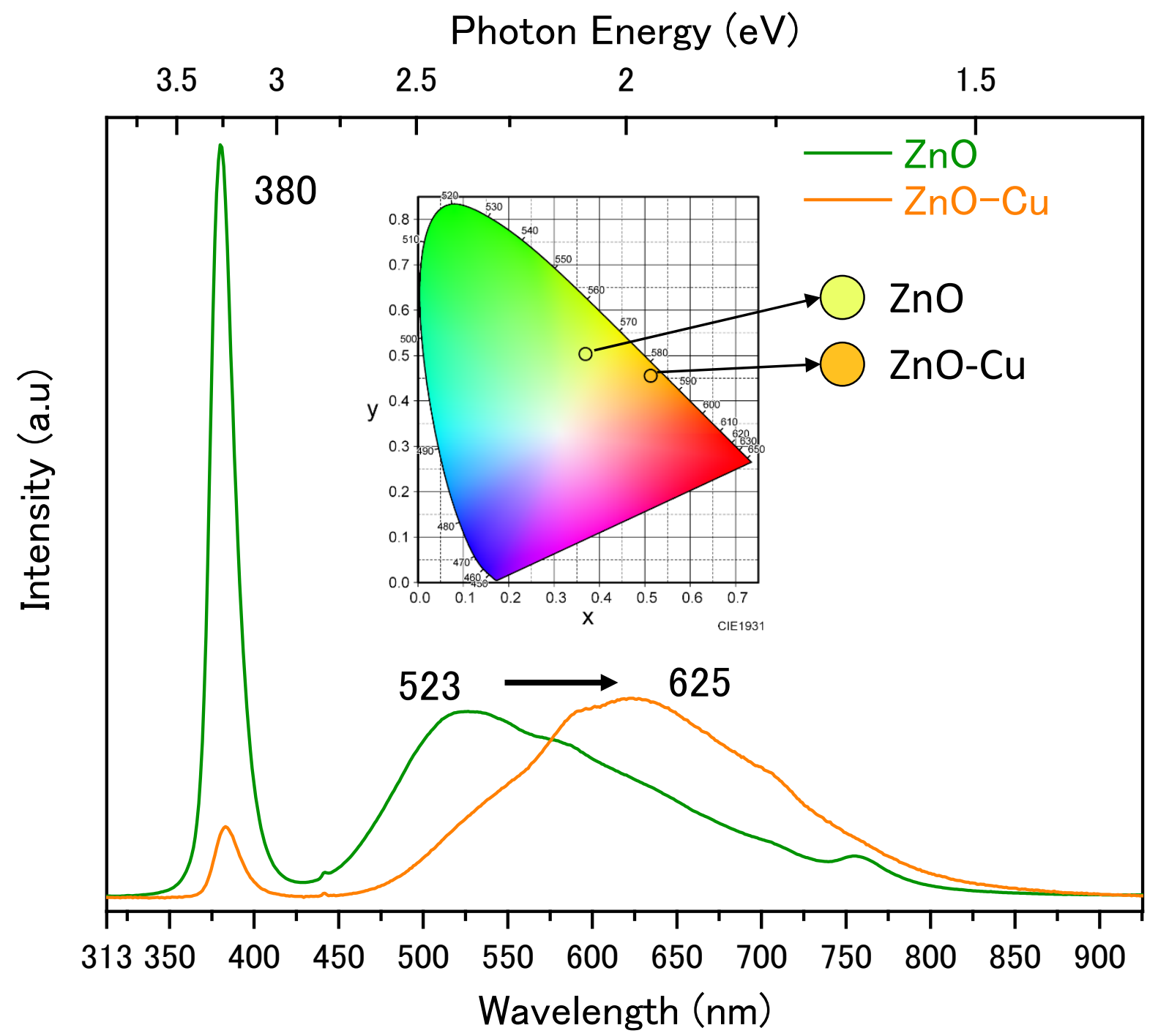

Fig. 6. (a) Photoluminescence spectra of perfect $\mathrm{ZnO}$ and $\mathrm{ZnO}-\mathrm{Cu}$ sample. Inset is color chromaticity diagram showing the color difference between $\mathrm{ZnO}$ and $\mathrm{ZnO}-\mathrm{Cu}$, yellowish green from $\mathrm{ZnO}$ and orange color from $\mathrm{ZnO}-\mathrm{Cu}$. 

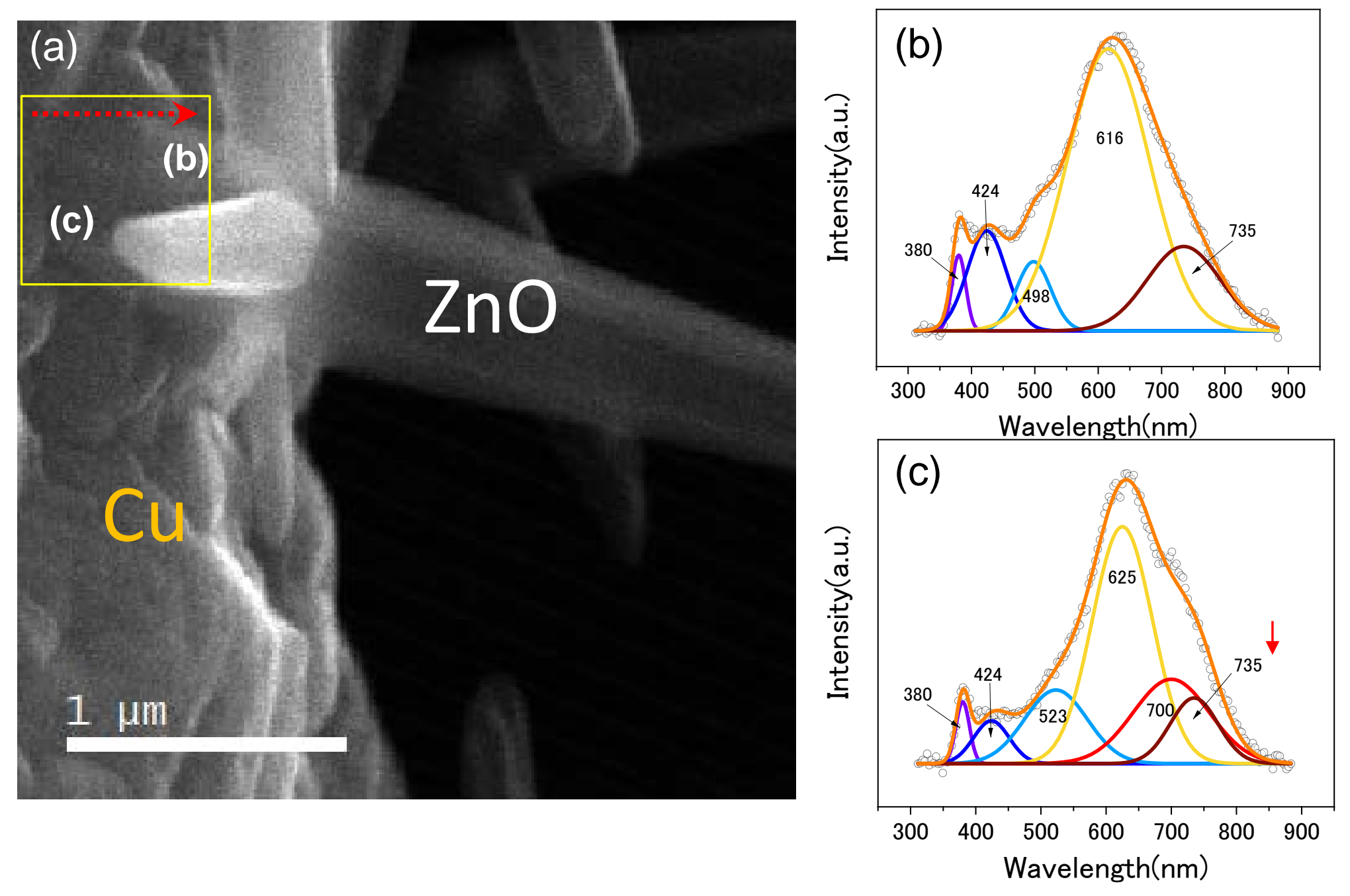

Fig. 7. (a) STEM backscattered electron image of $\mathrm{ZnO}-\mathrm{Cu}$. Yellow marker indicates the 2-D STEM-CL mapping region, covering $\mathrm{ZnO}-\mathrm{Cu}$ interface and $\mathrm{ZnO}$ bulk surface. Red line is the 2-D mapping direction. A distinguished CL point spectra were obtained from (b) $\mathrm{ZnO}$ surface and (c) ZnO-Cu surface. 
Fig. 8. (a) Photoluminescence spectra of $\mathrm{ZnO}-\mathrm{M}$ NRs according to ionization tendency ranking. Visible peaks vary according to the noble metals. PL spectra with Gaussian fitting of (b) $\mathrm{ZnO}-\mathrm{Au}$ (c) $\mathrm{ZnO}-\mathrm{Pt}$ (d) $\mathrm{ZnO}-\mathrm{Ag}$ (e) $\mathrm{ZnO}-\mathrm{Cu}$ (f) $\mathrm{ZnO}-\mathrm{W}$ (g) $\mathrm{ZnO}-\mathrm{Ni}$.
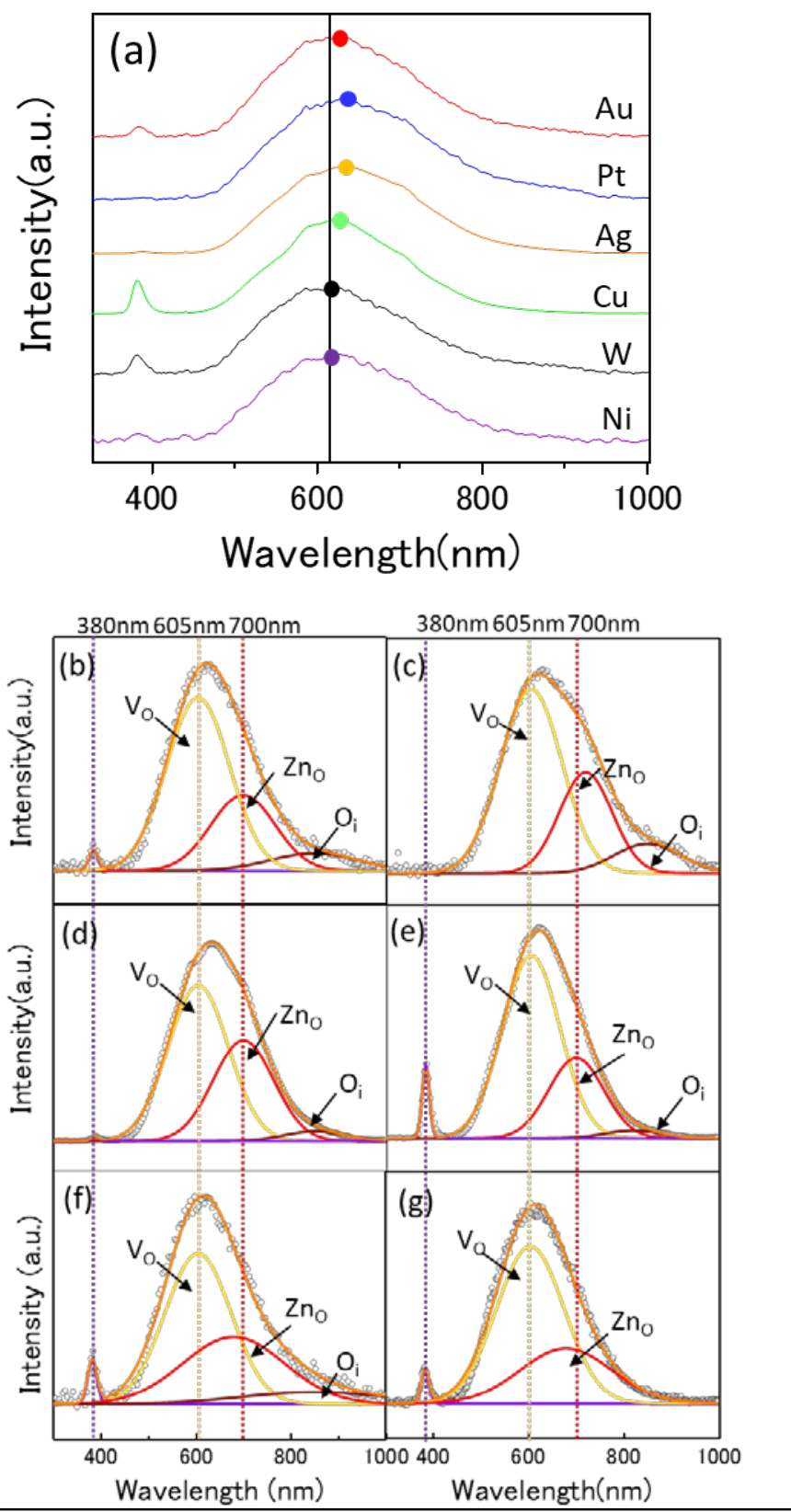

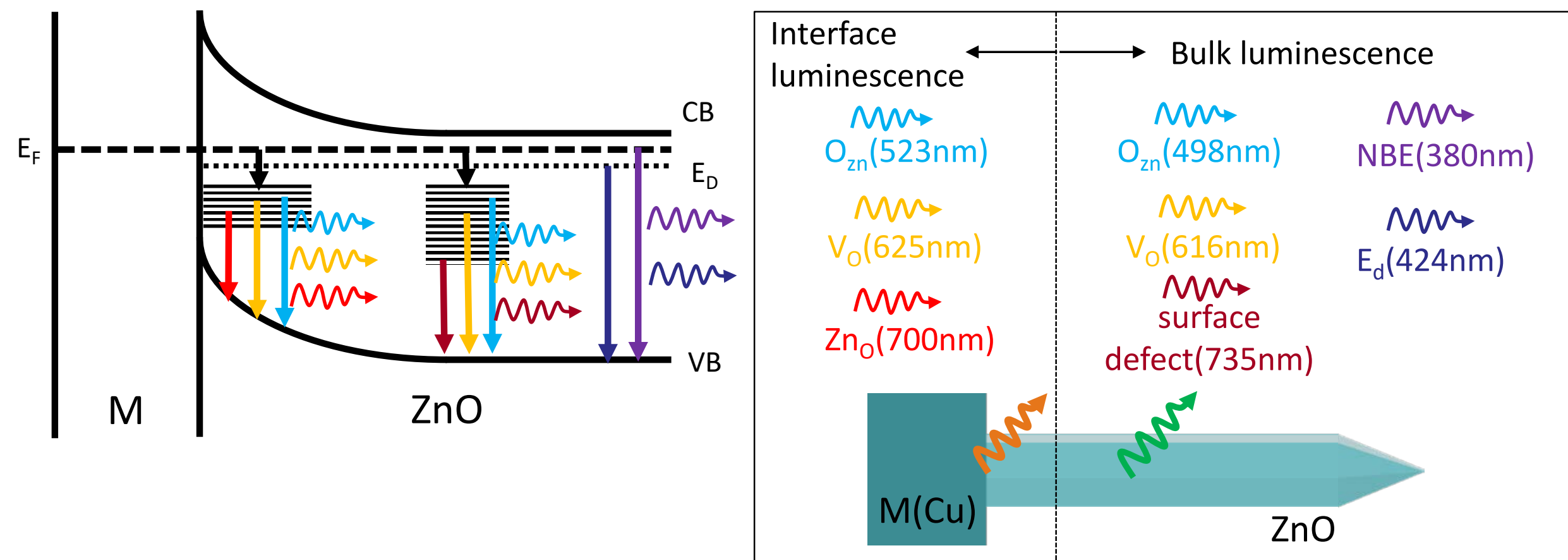

Fig. 9. Schematic illustration of ZnO-M NRs luminescence mechanism. 
Table 1. Work function and PL peak fitting assignment of $\mathrm{ZnO}-\mathrm{M}$ samples in Fig. 8.

\begin{tabular}{|c|c|c|c|c|c|c|}
\hline & $\mathrm{Au}$ & $\mathrm{Pt}$ & $\mathrm{Ag}$ & $\mathrm{Cu}$ & $\mathrm{W}$ & $\mathrm{Ni}$ \\
\hline Work function $(\mathrm{eV})$ & 5.1 & $5.65-6.1$ & $4.2-4.26$ & $4-4.65$ & $4.55-5.1$ & 5.1 \\
\hline $\mathrm{NBE}(\mathrm{nm})$ & 383 & - & 383 & 383 & 383 & 383 \\
\hline $\mathrm{V}_{O}(\mathrm{~nm})$ & 610 & 618 & 614 & 608 & 600 & 600 \\
\hline $\mathrm{Zn}_{O}(\mathrm{~nm})$ & 715 & 720 & 719 & 705 & 700 & 700 \\
\hline $\mathrm{O}_{i}(\mathrm{~nm})$ & 845 & 850 & 845 & 830 & 830 & 830 \\
\hline Total $(\mathrm{nm})$ & 625 & 631 & 630 & 624 & 619 & 619 \\
\hline
\end{tabular}


Luminescent properties of $\mathrm{ZnO}-\mathrm{M}$ heterostructures fabricated by Galvanic-submerged photosynthesis of crystallites

\section{SUPPLEMENTARY MATERIAL}

Kento Hiraiwa, Yuki Takahashi, Juinchi Mizuno, Melbert Jeem, Seiichi Watanabe 
Table S1. Weight change of $\mathrm{ZnO}-\mathrm{M}$ samples after G-SPSC. $\Delta \mathrm{V}$ is standard electrode potential difference of noble metals $\mathrm{M}$ with $\mathrm{Zn} . \Delta \mathrm{V}$ is the average value increment per unit area of $\mathrm{ZnO}$ NRs formation. Average value was taken after three times measurement.

\begin{tabular}{|l|r|r|r|r|r|r|}
\hline Metal $(\Delta \mathrm{V})$ & $\mathrm{Au}(2.3 \mathrm{~V})$ & $\mathrm{Pt}(1.95 \mathrm{~V})$ & $\mathrm{Ag}(1.6 \mathrm{~V})$ & $\mathrm{Cu}(1.2 \mathrm{~V})$ & $\mathrm{W}(0.89 \mathrm{~V})$ & $\mathrm{Ni}(0.5 \mathrm{~V})$ \\
\hline$\Delta \mathrm{n}\left(10^{-5} \mathrm{~mol} / \mathrm{cm}^{2}\right)$ & 2.53 & 1.35 & 0.78 & 0.65 & 0.69 & 0.61 \\
\hline
\end{tabular}


Table S2. Quantitative XPS analysis of ZnO-M samples within O 1s spectra.

\begin{tabular}{|l|r|r|r|r|r|r|r|r|r|}
\hline \multirow{2}{*}{ samples } & \multicolumn{4}{|c|}{$\mathrm{ZnO}$} & \multicolumn{3}{|c|}{$\mathrm{Zn}(\mathrm{OH})_{2} / \mathrm{V}_{\mathrm{O}}$} & \multicolumn{3}{c|}{$\mathrm{H}_{2} \mathrm{O}$} \\
\cline { 2 - 10 } & Peak(eV) & FWHM & percentage(\%) & Peak(eV) & FWHM & percentage(\%) & Peak(eV) & FWHM & percentage(\%) \\
\hline $\mathrm{ZnO}-\mathrm{Au}$ & 530.1 & 0.8 & 57.6 & 531.6 & 1.1 & 24.7 & 532.5 & 1.1 & 17.7 \\
\hline $\mathrm{ZnO}-\mathrm{Pt}$ & 530.1 & 0.7 & 63.9 & 531.5 & 0.9 & 29.4 & 532.3 & 0.6 & 6.7 \\
\hline $\mathrm{ZnO}-\mathrm{Ag}$ & 530.1 & 0.7 & 67.1 & 531.5 & 0.8 & 26.6 & 532.3 & 0.6 & 6.3 \\
\hline $\mathrm{ZnO}-\mathrm{Cu}$ & 530.4 & 0.7 & 63.0 & 531.6 & 0.9 & 23.3 & 532.4 & 0.8 & 11.2 \\
\hline $\mathrm{ZnO}-\mathrm{W}$ & 530.3 & 0.7 & 66.7 & 531.6 & 0.9 & 23.7 & 532.3 & 0.9 & 13.8 \\
\hline $\mathrm{ZnO}-\mathrm{Ni}$ & 530.3 & 0.7 & 53.3 & 531.6 & 0.9 & 24.6 & 532.3 & 1.1 & \\
\hline
\end{tabular}


KEEP IN VIEW (KIV) FIGURES \& TABLES 
Table3

Amount change of substance and weight change of $\mathrm{ZnO}$ on samples after UV irradiation. Fig. 7

\begin{tabular}{|l|l|l|l|l|l|l|}
\hline Metal $(\Delta \mathrm{V})$ & $\mathrm{Au}(2.3 \mathrm{~V})$ & $\mathrm{Pt}(1.95 \mathrm{~V})$ & $\mathrm{Ag}(1.6 \mathrm{~V})$ & $\mathrm{Cu}(1.2 \mathrm{~V})$ & $\mathrm{W}(0.89 \mathrm{~V})$ & $\mathrm{Ni}(0.5 \mathrm{~V})$ \\
\hline $\mathrm{m}(\mathrm{mg})$ & 79.37 & 86.35 & 436.6 & 375.5 & 427.6 & 344.0 \\
\hline $\mathrm{M}(\mathrm{mg})$ & 83.71 & 87.78 & 437.3 & 376.3 & 428.2 & 344.6 \\
\hline$\Delta \mathrm{w}(\mathrm{mg})$ & 4.34 & 1.43 & 0.774 & 0.820 & 0.606 & 0.640 \\
\hline$\Delta \mathrm{n}\left(10^{-5} \mathrm{~mol} / \mathrm{cm}^{2}\right)$ & 6.09 & 2.01 & 1.09 & 1.15 & 0.851 & 0.899 \\
\hline
\end{tabular}

$\Delta \mathrm{V}$ :Standard electrode potential difference with $\mathrm{Zn}$ m:Mass before UV irradiation M:Mass after UV irradiation $\Delta \mathrm{w}$ :Mass increase before and after UV irradiation $\Delta \mathrm{n}$ :Increase amount per unit area before and after irradiation 